exhibition. Augustus John celebrates his return with a fine portrait of the Hon. Vincent Massey; and Mr. R. G. Eves, R.A., has deposited as his diploma work his portrait of Sir Joseph Barcroft. The Rev. E. Schomberg, Master of Charterhouse (Ronald Gray), the late Dr. H. R. Rathbone (L. Campbell Taylor), and Sir Herbert Baker (A. K. Lawrence, R.A.) are other notable portraits. Physicians are well represented by Sir Robert Hutchison (James Gunn), the late Prof. Edward Mapother (A. R. Thomson, A.R.A.), and Dr. E. B. Gunson (James B. Manson). There is also a charming miniature of Dr. Cyril Horsford by his daughter.

Museum men will be pleased to see the miniature of Dr. Charles ffoulkes by Dorothy Garratt, and the sanguine by Robert Swan of Mr. F. W. Troup. Miss Helen Campbell has done a chalk study of Sir Dennison Ross.

Amongst the sculpture there must be mentioned the bronze bust of Lord Cadman (Donald Gilbert), the bronze bust of Sir David Milne-Watson (Eric Schilsky), and the model of a bronze memorial to Sir Archibald Denny (L. S. Merrifield). Miss Barbara Tribe has done an excellent bust of that distinguished soldier and master of Peterhouse, Lord Birdwood. Mr. Bertram Pegram exhibits a bust of Sir Daniel Lleufer Thomas, a welcome testimony to services to the University and National Museum of Wales, and Mrs. BingguelyLejeune has a bronze relief of that great patron of the sciences, Lord Nuffield.

\title{
DISTRIBUTION OF MARINE ORGANISMS
}

\begin{abstract}
$\mathrm{A}^{\mathrm{T}}$ $\mathrm{T}$ the general meeting of the Linnean Society of London on April 25, a discussion regarding the extent to which the distribution of marine organisms can be explained by, and is dependent on, the hydrographical conditions present in the great oceans was opened by Lieut.-Colonel R. B. Seymour Sewell.
\end{abstract}

After dealing with the main categories of marine organisms-plankton, nekton, and benthos-and defining the various types of plankton, Col. Sewell considered the ancient Tethys Sea and the effect of its subsequent closure on the distribution of corals. The view has often been advanced that species found to be limited to-day to the North Atlantic and northern part of the Indian Ocean are relics from this early Tertiary sea; but recent investigations have so greatly increased the number of these species that this explanation is unlikely. A study of the ancient group of Crinoids provides an alternative explanation, and suggests that, while some species have reached the Atlantic and Arctic Oceans from the centre of origin in the region of the Malay Archipelago through the Tethys Sea, others have been dispersed along lines which correspond closely with the surface and deep-water currents of the present day.

There can be no doubt that the character and direction of flow of marine currents have had a profound influence on the fauna and flora of different regions, and are sufficient to account for the frequency with which species are found to be cosmopolitan in their habitat. Further, the convergence zones set up in regions where the different current systems abut upon each other may provide temperature barriers across which only the most tolerant species are able to pass, and thus give us sharp boundary lines between two types of fauna or flora.

Detailed studies of various groups of animals and plants within the limits of a single ocean have produced an important body of evidence as to the correlation between the distribution of the organisms and the presence of water of a particular origin, as well as the direction and extent of flow of this water. This has been well shown in investigations on both phyto- and zoo-plankton of the North Atlantic, as well as on the diatoms of the Southern Ocean, and evidence is also accumulating that benthonic organisms may be affected in much the same way, as shown by recent work on seaurchins, barnacles and sponges.

A study of the various zoogeographical regions which have been delimited as the result of work on the surface plankton reveals that these correspond fairly closely with the surface currents, and that the main line of dispersal for such plankton runs from east to west. A systematic study of the weed-haunting Harpacticid Copepods or of the surface-living Calanoids suggests that a very large percentage of the species of these crustaceans must have originated in the region of the Malay Archipelago, and that the farther we get away from this region the smaller is the number of Indo-Pacific species to be found, as might be expected if their dispersal is due to the surface currents. Similar evidence has been provided by the distribution of other groups of animals and of the littoral algæ.

In regard to the deeper levels, a study of the distribution of the meso-planktonic Calanoids again shows a distinct correlation with the general trend of the mid-water and deep currents. In this group the centre of origin appears to have been largely 
in the North Atlantic, and their distribution can be shown to follow the lines of the deep currents from west to east. Investigations on the Scyphomedusæ of the Indian Ocean suggest that these organisms have followed the same route, but we find that their distribution in the Indian Ocean is limited by the recently discovered azoic area in the Arabian basin and the Gulf of Oman. In this area, between depths of about 500 and 1,250 metres, there is a marked deficiency of oxygen, and the effect of this is well shown in the vertical distribution of two species of Calanoid copepods within and without the affected area.

With regard to the nekton and the benthos, the movements of the water masses must play a part in the dispersal of the eggs and larval stages while these are planktonic. The distances to which such forms can be carried by currents, however, will depend partly on the rapidity of the current and partly on the length of the larval period, but at the same time a study of the bottom topography reveals the presence of a number of 'stepping stones' by means of which a species could pass from one ocean to another in a series of successive generations.

In conclusion, Colonel Sewell pointed out that the cosmopolitan habitat of many species might well be accounted for by the influence of ocean currents on distribution. Further, a uniformity of the fauna and flora has not yet been achieved in spite of the long period of time that has elapsed since the oceans assumed their present positions and connexions in the middle of Tertiary times; nor can this be achieved while new forms continue to make their appearance. The ability of a given species to obtain a cosmopolitan range seems to depend to a great extent upon the ocean in which it made its original appearance.

Dr. Maurice Burton dealt with the distribution of marine sponges, and stressed the importance of sound systematics as a preliminary to zoo-geographical investigation. He agreed with Colonel Sewell as to the important part played by ocean currents in the dispersal of species, and pointed out that the distances reached depend to a great extent upon the duration of the larval life. The metamorphosis of a larval sponge on the surface film, which has been recorded under laboratory conditions, might well have a decided effect upon the dispersal of certain forms in the sea.

Dr. Anna Hastings considered the distribution of antarctic and subantarctic Cellularine Polyzoa. She showed that the distribution of the species is very closely related to hydrographic conditions, only 20 per cent of subantarctic and antarctic species being common to the two regions as limited hydrographically by the Antarctic Convergence. A similar separation is noticeable, and usually even more marked, in the few other groups of animals for which data have been obtained.

On the other hand, the distribution of the genera of antarctic Cellularine Polyzoa does not appear to be specially related to hydrological conditions. Their distribution points to eastern rather than western affinities, that is, with the Australasian, Malayan and Japanese faunas rather than American. This is also found in other groups, but not in the antarctic Echinoderms (D. D. John, 1937). These tendencies are difficult to relate to present hydrological conditions, and are more probably due to interrelations of the geological history of the region and the phylogeny of the groups.

Mr. J. R. Norman pointed out that fishes, being for the most part active swimmers, are not dependent upon the ocean currents for their distribution to nearly the same extent as the invertebrates already mentioned, although these may be an important factor in transporting pelagic eggs and larval stages, as in the case of the European eel. In the case of coastal fishes, including the littoral forms as well as those occurring at no great distance from the shores in water down to about 500 metres in depth, the most important hydro. logical factor influencing their distribution is the temperature of the sea. By taking the mean annual surface isotherms of $6^{\circ} \mathrm{C} ., 12^{\circ} \mathrm{C}$, and $20^{\circ} \mathrm{C}$. respectively, it has proved possible to delimit a series of zones of distribution in the sea, each with its more or less peculiar types of fishes. For example, the distribution throughout the world of the genus Sardina has been shown to lie roughly within the area bounded by the isotherms of $12^{\circ}$ and $20^{\circ}$. The isotherm of $12^{\circ}$ runs very roughly to the mouth of the English Channel, and it is just here that such warm-water forms as the pilchard, anchovy and red mullet are replaced by the herring, cod and plaice, and other cold-water types. This is also near the southern limit of the salmon and trout as marine fishes.

The islands of Tristan da Cunha and St. Paul, lying in the southern Atlantic and the southern Indian Ocean respectively, are about 4,000 miles apart but situated more or less on the same mean annual surface isotherm : there are certain species of fish common to these islands but found nowhere else. The fact that the Antarctic Drift runs direct from one island to another may have been a factor in assisting the spread of these fishes. There are about 90-100 species of fishes commonly found in the Patagonian - Falkland Islands region, but only three of these are found at the island of South Georgia, a bare 800 miles away but separated by the Antarctic Convergence, corresponding closely to the isotherm of $6^{\circ} \mathrm{C}$.

Of the oceanic fishes, the pelagic forms, although 
they appear to have on the whole a wider distribution than most coastal fishes, still seem to be limited mainly by temperature. In the case of the abyssal forms, the contour of the sea floor may play an important part in limiting their range, and it may be noted that the submarine ridge running from Scotland to Iceland and Greenland, less than 1,000 metres in depth, is the northern limit of the Macruridæ, the most characteristic family of bottom-living oceanic fishes. Our knowledge of the distribution of the bathypelagic fishes is still very incomplete, but it may be said that a number of them have a cosmopolitan range and that recent investigations have tended to add greatly to this number. Some of them are capable of extensive vertical migrations, and it may be that they are able to negotiate barriers which would be effective in limiting the spread of coastal fishes.

Dr. Stanley Kemp emphasized the importance to the general question of marine distribution of the comparative stability of species in the sea, and instanced the occurrence of identical species of fish and crustacea on both sides of the Isthmus of Panama in support of the view that species can remain identical over a long period of time. He thought that this would account for some of the instances of bipolarity, and mentioned a Euphausian common in the north and south but absent over a large stretch of the middle Atlantic. If species have remained unaltered for long periods of time, any arguments which base distribution upon existing ocean currents must be fallacious.

As an example of the adaptation of a planktonic fauna to hydrographical conditions Dr. Kemp mentioned the work of Mackintosh, who had shown that plankton at the time it approaches the Antarctic Convergence sinks to a deeper level and in this way is carried back to its proper habitat in the Antarctic. The deep-water prawns of the genus Acanthephyra, which are abundant in tropical and temperate parts of the oceans, have recently been investigated in detail, and have been found to have become differentiated in the various oceans. The species are separated by quite trivial characters (the number of spines on the telson), which are, however, astonishingly constant. One species in the Atlantic shows a widely discontinuous distribution.

Dr. G. P. Bidder wondered whether the length of the larval life was really so important a factor in the dispersal of sponges, and suggested that in the case of calcareous sponges these might be carried to new localities on the bottoms of ships. He pointed out that the largest and finest specimens found at Naples and Plymouth were collected from vessels anchored in harbour for a month or so.

Prof. W. Garstang suggested that an interesting approach to the problem as far as pelagic animals are concerned would be to tabulate the differences in distribution of those forms with large and small larval stages respectively.

\section{OB ITUAR IES}

\section{Prof. Jules Schokalsky}

$\mathrm{T}$ HE distinguished Russian geographer Prof. Jules Schokalsky died in Leningrad on March 26 at the age of eighty-four. He was widely known throughout Europe and America, where he made many friends at international scientific gatherings. As a boy he lived much in the country and acquired a love of Nature by his comradeship with a son of the poet Pushkin, and this æsthetic sentiment opened the way to serious scientific study. He led a life of ceaseless activity from the time he entered the Naval School at St. Petersburg in 1874 until his death, and for forty-five years I have had the privilege of enjoying his helpful friendship. Even the shock of the Russian revolution of 1917 did not check the continuity of his work; to him science was superior to politics. $\mathrm{H}_{\theta}$ continued under the Soviet system in Leningrad to give full expression to the enthusiasm for oceanography and cartography which had animated him during half a century under the Empire.

Schokalsky studied at the Naval School in St. Petersburg, and in 1877 he went to sea as a midshipman in the Imperial Navy. After two years he turned to shore work connected with naval research and education, spending three years at the National Physical Observatory under the great meteorologist, Dr. H. Wild. After this he joined the teaching staff at the Naval Academy and was professor and then emeritus professor of physical geography, meteorology and oceanography from 1910 until 1930 . For a time he was librarian of the Central Library of the Russian Admiralty, and he ended his academic career and his life as professor in the University of Leningrad. He found time for innumerable honorary appointments, culminating in the presidency of the Imperial Russian Geographical Society, which he held for many years, and on his retirement was appointed honorary president of the same Society under the U.S.S.R.

He was a tireless writer with nearly five hundred entries of publications under his name, many of them, of course, being official reports, summaries and criticisms. His most important book was the "Treatise on Oceanography", in Russian, published in 1917. This is a work of originality and distinction, showing much ingenuity in the design of illustrative 